\title{
The Differences in Coaching Behaviors between Individual and Team Sports at College Varsity level 大學生代表隊個人與團隊運動項目教練行為之間的差異
}

\author{
Howard Z. ZENG Raymond W. LEUNG \\ Department of Physical Education and Exercise Science, \\ The City University of New York, Brooklyn College, USA
}

\author{
Wei BIAN Wenhao LIU \\ Physical Education Department, \\ Slippery Rock University, \\ Slipery Rock, USA
}

\section{曾振豪梁偉文}

美國紐約市立大學布魯克林學院體育及運動科學系

\section{市薇劉文浩}

美國賓夕法尼亞滑石大學體育學系

\begin{abstract}
This study examined the differences in coaching behaviors between individual sports (ISs) and team sports (TSs). Participants were head-coaches of ten varsity teams from a college in the USA. Twenty practice sessions (two practices per coach) were videotaped and the Arizona State University Observation Instrument was used for data collection. A 2 x 2 MANOVA (sports $\mathrm{x}$ observations) revealed that significant differences in five coaching behaviors between the two types of sports. Specifically, ISs coaches demonstrated significantly greater $(\mathrm{p}<.05)$ rate per minute (RPM) than did TSs coaches in Preinstruction $(\mathrm{M}=1.41 \pm .12$ vs. $.73 \pm .13)$, Questioning $(\mathrm{M}=.55 \pm .11$ vs. $.29 \pm .31)$, and Praise $(\mathrm{M}=.84 \pm .37$ vs. $.36 \pm .38)$. TSs coaches demonstrated significantly greater $(\mathrm{p}<.05)$ RPM than did ISs coaches in Postinstruction $(\mathrm{M}=$ $1.28 \pm .18$ vs. $.56 \pm .06)$ and Hustle $(\mathrm{M}=.89 \pm .12$ vs. $.13 \pm .06)$. No significant differences $(\mathrm{p}>.05)$ were identified in Concurrent Instruction, Positive Modeling, Negative Modeling, Scold, and Management behaviors between the coaches. In conclusion, the coaches from the ISs and TSs employed different coaching behaviors that reflected the features of their specific sports.
\end{abstract}

Key words: Instruction, Feedback, and Hustle.

\section{摘 要}

本研究檢驗了大學生代表隊個人與團隊運動教練行為之間的差異。研究對象為位於美國東部一所大學的10支運動代表隊的 主教練。研究者在他們進行正常訓練時對10名教練員的教練行為進行了録像記錄 (總共錄了20堂訓練課，每名教練員兩堂)。資 料採用亞里桑納州立大學系統觀測儀收集。通過 $2 \times 2$ 多元方差分析檢驗，在 個人與團隊運動之間有五種教練行為顯出明顯差異 $(\mathrm{p}<.05)$ 。具體如下：個人運動教練比團隊運動教練使用了明顯多的訓練前指導 $(\mathrm{M}=1.41 \pm .12$ vs. $.73 \pm .13) ，$ 訓練中提問 $(\mathrm{M}=.55 \pm .11$ vs. $.29 \pm .31)$ 和表揚 $(\mathrm{M}=.84 \pm .37$ vs. $.36 \pm .38)$; 團隊運動教練比個人運動教練使用了明顯多的訓練後指導 $(\mathrm{M}=1.28 \pm .18$ vs. $.56 \pm .06)$ 和訓練中催促 $(\mathrm{M}=.89 \pm .12$ vs. $.13 \pm .06)$ 。然而, 個人與團隊運動的教練在使用訓練中指導正或負面 示範叱責和組織/管理等教練行為時沒有明顯差異 ( $\mathrm{p}>$.05)。結論：個人與團隊運動項目的教練使用了不同的教練行為而這些教練 行為反映了他們所教運動項目的特點。 


\section{Introduction}

In athletic coaching effectiveness research, such as how time is spent in practice and game settings and how coaching behaviors function appropriately during a practice segment has been an important topic in the area of coaching effectiveness (Darst, Zakrajsek \& Mancini, 1989; Jones, Housner \& Kornspan, 1997; Ruppert \& Buschner, 1989; Sherman, Fuller \& Speed, 2000). Numerous studies conducted by sport pedagogical researchers (e.g., Lacy \& Darst, 1985; Lacy \& Goldston, 1990; Millard, 1996; Segrave \& Ciancio, 1990; Sherman, Fuller \& Speed, 2000) have involved in how coaching behaviors function using systematic observation technique in team sports settings. For example, Lacy and Darst (1985) examined coaching behaviors on 10 winning high school football coaches using the Arizona State University Observation Instrument (ASUOI). Lacy and Darst (1985) found that the high school football coaches utilized the 11 coaching behavior categories in total rate per minute (RPM) was significantly higher in the preseason than early season and later season. Moreover, The 11 coaching behaviors exhibited by the coaches were significantly higher during their team or group practice segments than during their individual warm-up and conditioning exercise segments. Additionally, the Preinstruction and Postinstruction behavioral categories were employed significantly more often than other non-instructional behaviors over the season (Lacy \& Darst, 1985).

Lacy and Goldston (1990) also used the ASUOI observing and analyzing coaching behaviors from 10 high school women's basketball teams (5 Male coaches and 5 female coaches). Through comparisons, they found that female coaches tend to employ more Preinstruction, Management and Postinstruction behaviors than male coaches; female coaches also tend to use more Praise behavior and less Scold behavior than male coaches; the major coaching behavioral category was Instructional behaviors (nearly 50\%); other behaviors such as Hustle, Praise and Scold were about 19\%; and the most frequently utilized behaviors by all coaches across gender were Concurrent Instruction, Postinstruction, and Management.

Millard (1996) examined the differences of coaching behaviors between male and female high school soccer coaches by using the Coaching Behavior Assessment System. Participants were 58 high school soccer coaches
(29 male and 29 female). She found that the female coaches appeared to be younger and have less coaching experience, but possess more actual experience as athletes than did the male coaches; the male coaches appeared to engage in more Control and technical Instruction behaviors than did the female coaches; and the male coaches also appeared to engage in less Encouragement behaviors than did the female coaches.

Moreover, Sherman, Fuller and Speed (2000) explored gender differences with regard to coaching behaviors among 312 male and female athletes (male = 170; and female = 142). The examined coaching behavior categories were: Training and Instruction, Positive Feedback, Democratic, Social Support, and Autocratic. What they found were: the coaching behaviors exhibited from the three team sports (football, basketball and netball) were similar across gender although some slight differences in coaching behavioral preferences were noted, the similarities seemed to outshine any differences among all the observed coaches.

Other than team sport, Claxton (1988) conducted a research in a dual game sport; he examined the coaching behaviors of successful and unsuccessful high school tennis coaches using the ASUOI. He found that less successful coaches tend to use more Praise behavior than successful coaches, while more successful coaches tend to use more Questioning behavior than less successful coaches.

In brief, over the last three decades, researchers in the area of coaching effectiveness have done numerous studies with regard to how coaching behavior function in team sports, such as football, basketball, baseball, volleyball and soccer. These studies were important and meaningful in helping coaches and athletes understanding how coaching behaviors work in team sports environments, and those research literatures have contributed to the art of athletic coaching. However, little information and study have covered in terms of how coaching behaviors function and improve the coaching effectiveness in individual sport. Jones, Armour, and Potrac (2002) pointed out that there is limited research on the field of athletic coaching in which the coaches are engaged. Myers, Wolfe, and Feltz (2005) also indicated that considerable research has been conducted on addressing coaching behaviors in team sports; little study and literature is available on addressing coaching 
behaviors in individual sports. Team sport is not only type of sports in the arena of competitive sports. Individual sport (such as track and field, gymnastics, and swimming) is another type sport. Questions have been raised, such as: do coaches in individual sports use the same coaching behaviors as those coaches in team sports? What kinds of coaching behaviors would be more important or essential for individual sport? Coaches and athletes are still waiting for the right answers. Conducting a study, therefore, in examining and comparing the differences in coaching behaviors between individual sport and team sport at varsity level was necessary and significant. Thus, the purpose of this study was to examine the differences in coaching behavior between individual sport and team sport, and to extend the knowledge in how coaching behaviors function into the area of coaching effectiveness.

\section{Methods}

\section{Participants}

The participants were 10 head coaches and these coaches were selected from a National collegiate Athletic Association (NCAA) Division III college in the United States, in which five were from individual sports: men's and women's swimming teams (coaching by the same coach), track and field, and gymnastics; and five were from team sports: men's and women's volleyball, men's soccer, men's basketball, and women's softball. All coaches in the present study had five or more years' experience in their current positions. An Informed Consent Form was signed by the participants prior to the beginning of the investigation that was approved by the Institutional Review Board (IRB) of the college.

\section{Instrumentation}

All data that reflect coaching behaviors in the present study were coded using Arizona State University Observation Instrument (ASUOI, Lacy \& Darst, 1989); included the following 11 coaching behaviors: Preinstruction, Concurrent Instruction, Postinstruction, Questioning, Positive Modeling, Negative Modeling, Hustle, Praise, Scold, Management, and Uncodeable. Lacy and Darst (1989) indicated that ASUOI was a refined and validated systematic observation instrument based on many previous live and videotaped researches from the field of athletic coaching. With regard to the reliability of the ASUOI, Lacy and Darst (1989) stated that inter-observer agreement (IOA) must reach an $85 \%$ criterion. They also indicated "during interobserver agreement checks, the observers are situated far enough apart so as to not influence the recording behaviors of each other. These interobserver agreement checks ensure that the observers are reliable" (p. 63). With regard to the validity of the ASUOI, Lacy and Darst (1989) stated that the definitions of the behavioral categories have face and content validity, because the behavioral categories in the ASUOI are very specific and have very narrow definitions, face validity being assumed. Furthermore, the content validity in the ASUOI is confirmed through literature review in the field of sport pedagogy (Lacy \& Goldston, 1990; Millard, 1996; Sherman, Fuller \& Speed, 2000; Zeng \& Leung, 2008).

Procedures of Videotaping and Coding. The following videotape procedures were executed: (a) delivered the Informed Consent Form and the Cover Letter to the participants; (b) explained the design of this study to the participants; and (c) videotaped two practice sessions for each coach/team. During the videotaping, the participants wore a wireless microphone and the camcorder was placed in a non-intervention location to control the reactive effects. Lacy and Darst (1989) stated that using event recording technique or interval recording technique to code the coaching behaviors is depend on the need of researcher. The current investigation utilized the event recording technique. Lacy and Darst (1989) described that "event recording involves placing a tally mark on the coding form each time one of the predefined behavior categories is observed" (p. 372). The tallies in each behavior category were transferred into rate of per minute (RPM). During the coding procedure, when a specified predefined behavior was observed on the tape, that behavior was recorded on the coding sheet. Each coaching session observed on the tape was timed by a stopwatch to the nearest minute to determine the RPM, so that each behavioral was coded and quantified. The RPM for each behavioral category was calculated by dividing the total tallies of each category from the minutes of observation.

Observers Training. Two observers were trained in the use of the ASUOI. Four-phase protocol as described by Siedentop and Tannehill (2000) was followed. First, the observers studied over the instrument; second, the observers had a communication on understanding the definitions of each coaching behavior; third, the observers get familiar with the coding process by using the coding sheet over and over again; and fourth, the observers 
practiced coding from the video tapes together until they reached the criterion of $85 \%$ agreement in all 11 behavioral categories. After four practice coding sessions were conducted, the interobserver agreement reached $85 \%$ agreement. Interobserver reliability for the ASUOI was calculated using the "General formula for reliability of observation" (Siedentop \& Tannehill, 2000).

\section{Statistical Analysis}

The statistical analysis was the $2 \times 2$ factorial multivariate analysis of variance (MANOVA) with two repeated measures factors (sports $x$ observations) aim at examining the differences and similarities among the vectors from the 11 dependent variables. The rates of per minute (RPM) from each coaching behavior were used as the data. After the $2 \times 2$ factorial MANOVA revealed a significant difference in the sports factor, a stepwise discriminant function analysis (DFA) was employed to identify which coaching behaviors are more important or essential for either individual or team sports coaches. Finally, a bar chart was utilized to demonstrate the differences and similarities with regard to the 11 coaching behaviors from the ASUIO (Lacy \& Darst, 1989) for the coaches who coach in either individual sports or team sports.

\section{Results}

The objective of the present study was to examine the coaching behavior differences between the selected individual sports and team sports. The descriptive statistics for 11 coaching behaviors from the ASUOI in RPM for the participants were presented in Table 1. The interobserver agreement (IOA) for two observers was $89.2 \%$ (the IOA value over the 11 behavioral categories range from .853 to .925). The results of $2 \times 2$ (Sports $x$ Observations) factorial MANOVA with two repeated measures factors were presented in Table 2. A significant $(\mathrm{p}<.05)$ difference was found for the sports factor, $\Lambda$ $=.000, \mathrm{~F}=1390.802$. No significant $(\mathrm{p}>.05)$ difference was found for observations factor $\Lambda=.047, \mathrm{~F}=5.083$. The interaction (Sports $\mathrm{x}$ Observations) was not significant $(\mathrm{p}>.05), \Lambda=.273, \mathrm{~F}=.665$.

Table 1. Descriptive Statistics of 11 Pedagogical Behaviors from ASUOI in Rate of Per Minute (RPM) for Coaches in Individual and Team Sports $(\mathrm{N}=10)$.

\begin{tabular}{|c|c|c|c|c|c|c|c|c|}
\hline \multirow[b]{2}{*}{ Behav. } & \multicolumn{2}{|c|}{$\begin{array}{l}\text { I-Sports } \\
\text { OBS. } 1\end{array}$} & \multicolumn{2}{|c|}{$\begin{array}{l}\text { I-Sports } \\
\text { OBS. } 2\end{array}$} & \multicolumn{2}{|c|}{$\begin{array}{l}\text { T-Spots } \\
\text { OBS. } 1\end{array}$} & \multicolumn{2}{|c|}{$\begin{array}{l}\text { T-Spots } \\
\text { OBS. } 2\end{array}$} \\
\hline & $M$ & $S D$ & $M$ & $S D$ & $M$ & $S D$ & $M$ & $S D$ \\
\hline PREI & 1.36 & .12 & 1.46 & .07 & .73 & .13 & .72 & .05 \\
\hline CONI & .94 & .03 & .89 & .12 & .92 & .05 & .84 & .05 \\
\hline POSI & .55 & .04 & .56 & .06 & 1.33 & .15 & 1.23 & .18 \\
\hline QUES & .53 & .11 & .56 & .11 & .26 & .05 & .31 & .04 \\
\hline PO-M & .11 & .04 & .10 & .05 & .08 & .08 & .12 & .05 \\
\hline NE-M & .01 & .01 & .00 & .00 & .00 & .00 & .00 & .01 \\
\hline HUST & .11 & .06 & .14 & .04 & .87 & .12 & .91 & .04 \\
\hline PRAI & .91 & .04 & .77 & .37 & .34 & .07 & .38 & .06 \\
\hline SCOL & .03 & .01 & .05 & .05 & .06 & .02 & .13 & .03 \\
\hline MANA & .13 & .03 & .14 & .03 & .36 & .05 & .42 & .09 \\
\hline
\end{tabular}

Notes: (a) I-Sport $=$ Individual Sport; T-Sport $=$ Team Sport; OBS.= Observation .

(b) PREI = Preinstruction; CONI = Concurrent instruction; POSI = Postinstruction; QUES = Questioning;

PO-M = Positive Modeling; NE-M = Negative Modeling; HUST = Hustle; PRAI = Praise;

SCOL = Scold; MANA = Management; and UNCO = Uncodeable. 
Table 2. 2 x 2 Repeated Measures MANOVA Comparing Coaching Behaviors in Rate of Per Minute (RPM) for Coaches in Individual and Team Sports on Two Observation Days (Ob.Days) $(\mathbf{N}=10)$.

\begin{tabular}{lcccccc}
\hline Source & $\begin{array}{c}\text { Wilks' } \\
\text { Lambda }\end{array}$ & $\begin{array}{c}\mathbf{F} \\
\mathbf{d f}\end{array}$ & $\begin{array}{l}\text { Hypo } \\
\mathbf{d f}\end{array}$ & Error & $\mathbf{p}$ & $\boldsymbol{\eta}^{2}$ \\
\hline Ind./Team & .000 & 1390.802 & 4 & 1 & $<.05$ & 1.000 \\
Ob.Days & .047 & 5.083 & 4 & 1 & $>.05$ & .953 \\
$\mathrm{I} / \mathrm{T} *$ Days & .273 & .665 & 4 & 1 & $>.05$ & .727 \\
\hline
\end{tabular}

Note: Ind. = individual sports; Team $=$ team sports; Ob.Days $=$ observation days; $\mathrm{I} / \mathrm{T}=$ individual $/$ team sports

A stepwise discriminant function analysis (DFA) was computed to identify which behavioral categories were used more frequently for the participants with respect to the 11 coaching behaviors. As a result, function 1 (sports factor) was significant, $\Lambda=.000$; Canonical correlation $=1.000 ;$ Chi Square $=47.169 ; \mathrm{p}<.05$. A summary of the DFA was presented in Table 3. The differences and similarities were as follows: (a) coaches who were coaching in the individual sports used significantly $(\mathrm{p}$ $<.05)$ more Preinstruction and Questioning behaviors than those coaches in the team sports; (b) coaches who were coaching in the team sports used significantly ( $p$ $<$.05) more Postinstruction and Hustle behaviors than those coaches in the individual sports; (c) the coaches in both individual and team sports appeared to use similar $(\mathrm{p}>$.05) amount of Concurrent Instruction, Negative Modeling, Scold behaviors; and (d) the data in Praise, Positive Modeling, Management, and Uncodeable behavioral categories could not be entered in the stepwise analysis.

Table 3. Discriminant Function Analysis to Identify which Variables were more important/Essential for the Coaches in Individual/Team Sports $(N=10)$.

\begin{tabular}{lllccc}
\hline Variable & $\begin{array}{l}\text { Wilks } \\
\text { Lambda }\end{array}$ & $\mathbf{p}$ & $\begin{array}{c}\text { Unstand. } \\
\text { Coeffs. }\end{array}$ & $\begin{array}{c}\text { Stand. } \\
\text { Coeffs. }\end{array}$ & $\begin{array}{l}\text { Structure } \\
\text { Coeffs. }\end{array}$ \\
\hline HUST & .045 & .000 & 283.693 & 24.910 & .025 \\
POSI & .024 & .000 & 233.193 & 25.550 & -.004 \\
CONI & .005 & .000 & -500.373 & -23.443 & -.003 \\
QUES & .002 & .000 & 190.649 & 14.126 & -.011 \\
NE-M & .001 & .000 & 1157.427 & 5.884 & -.001 \\
PREI & .000 & .000 & 6.764 & 6.275 & .019 \\
SCOL & .000 & .000 & 118.180 & 2.695 & .003 \\
\hline \multicolumn{7}{c}{} \\
\hline
\end{tabular}

Notes: HUST = Hustle; POSI = Post instruction; CONI = Concurrent instruction; QUES = Questioning;

NE-M = Negative Modeling; PREI = Preinstruction; $\mathrm{SCOL}=$ Scold.

Among the 11 dependent variables, therefore, the DFA identified that Preinstruction and Questioning behaviors have more important or essential meaning for the coaches from individual sports; Postinstruction and Hustle behaviors have more important or essential meaning for the coaches from team sports. Furthermore, the differences and similarities in RPM with regard to the 11 coaching behaviors for the participants were summarized in Figure 1. As can be seen on Figure 1, six behavioral categories displayed remarkably differ 
from in terms of the RPM value over the two observed occasions. In summary: (a) coaches in individual sports utilized significantly more Preinstruction, Questioning and Praise behaviors than that of the coaches in team sports; and (b) coaches in team sports utilized significantly more Postinstruction, Hustle and Management behaviors than that of the coaches in individual sports. Additionally, quite similar amount of the RPM for Concurrent Instruction, Positive Modeling, Negative Modeling, Scold, and Uncodeable behavioral categories was observed from the coaches in the selected individual and team sports. Note that, because there were no independent group variables, the Levene test is not needed to determine homogeneity of variance across independent groups, and the Box M test is not needed either.

Figure 1. A bar chart for comparing the average scores of two observations for 11 coaching behaviors in rate of per minute (RPM) data for the coaches of individual and team sports.

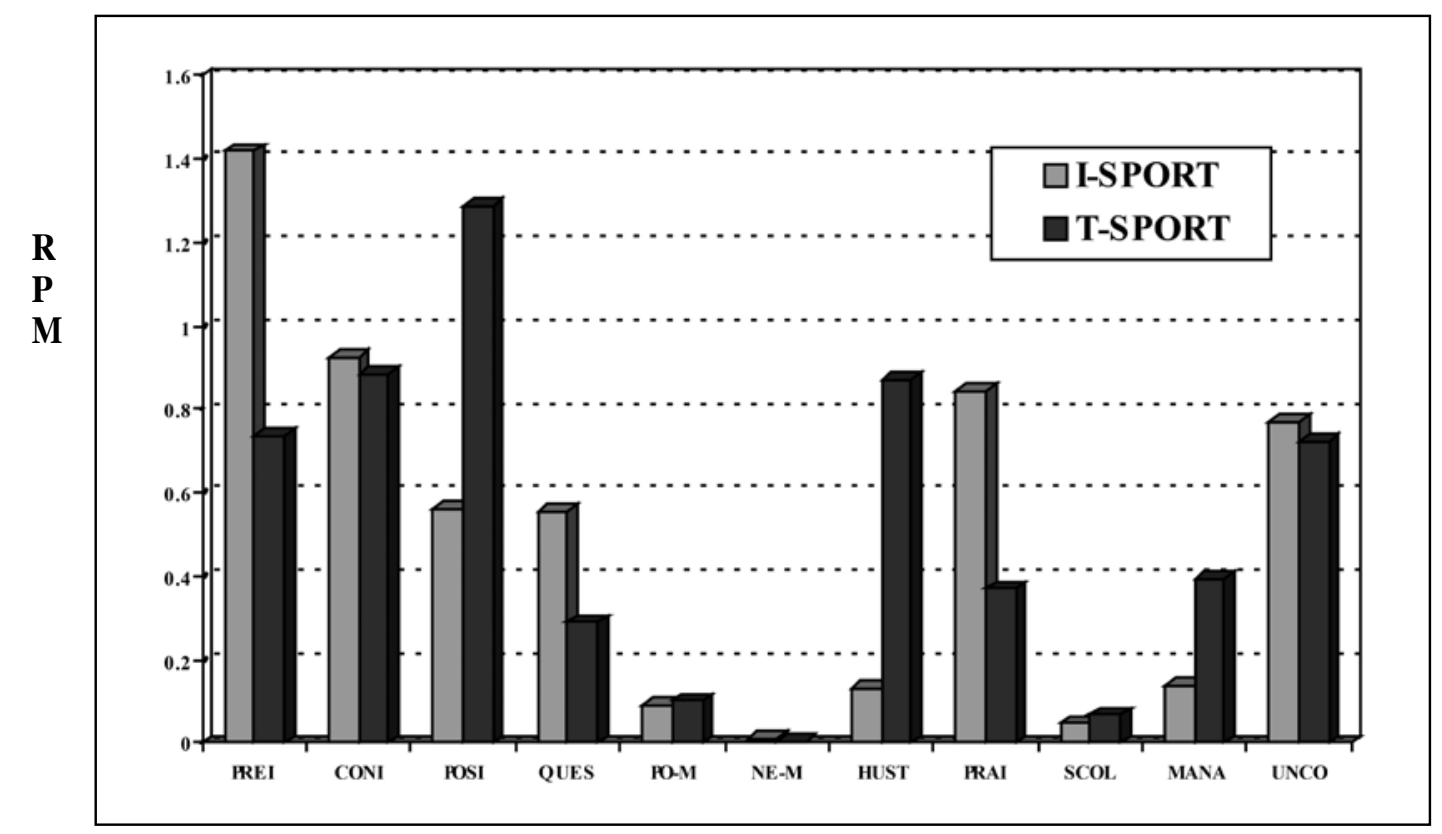

Note. $\quad$ PREI = Preinstruction; CONI = Concurrent instruction; POSI = Post instruction; QUES = Questioning;

PO-M = Positive Modeling; NE-M = Negative Modeling; HUST = Hustle; PRAI = Praise;

SCOL = Scold; MANA = Management; and UNCO = Uncodeable

\section{Discussion}

The aims of this study was to examine the differences in coaching behavior between individual sport and team sport, and to extend the knowledge in how coaching behaviors function in different sport practice settings. Based on the above analyses, this discussion section would focus on the follows: (a) Coaches in selected individual and team sports did not employ the same amount of behaviors in Preinstruction, Questioning, Postinstruction and Hustle coaching behaviors. Preinstruction and Questioning coaching behaviors may have more important meaning for the coaches in individual sports, and Postinstruction and Hustle behaviors may have more important meaning for the coaches in team sports. (b) Coaches in both individual and team sports did apply similar amount of Concurrent Instruction, Positive Modeling, Negative Modeling, Scold, and Uncodeable coaching behaviors in their athletic practice settings. And (c) which coaching behaviors would be more important or essential for individual sport and team sport.

The findings of this study may have something to do with the follows: First, coaches in individual sports, such as track and field, gymnastics, and swimming, have to set up and direct the practice tasks/goals for each athlete at the beginning of every practice; then in the middle of the practice or whenever the coach thinks it necessary, he 
or she may ask or communicate with athletes about how they are doing with the practice tasks. Oftentimes coaches in the individual sports may check athletes' understanding or cognition about key elements of the drills, or how athletes feel about certain technical components that they are practicing. This is why individual sports coaches use Preinstruction and Questioning behaviors more frequently than the team sports coaches.

Second, coaches in team sports, such as basketball, volleyball and soccer, have to provide a lot of feedback to their athletes in order to enable athletes to apply correct techniques to perform better teamwork, and to carry out tactics and strategies; particularly, coaches in team sports are more likely to hustle their athletes, in order to stimulate and challenge athletes physically and mentally. In addition, athletes in team sports already know the skills, the tasks and the expectations because they have gone through those practice routines over and over again. Oftentimes the coaches only need a few Preinstruction to make the practice tasks clear, to interpret the key components of the drills, and then put the athletes into the practice setting. Generally, coaches in team sports are more concerned about how their athletes cooperate with each other, in other words the quality of team performance; therefore, they always try to provide accurate, meaningful and pertinent feedback to their athletes. This is why team sports coaches employed Postinstruction and Hustle behaviors more frequently than the individual sports coaches.

On the other hand, for the finding that no significant difference exist in the observation occasion factor and the interaction (sports $\mathrm{x}$ observations) factor (see Table 2), the following situations may able to explain this finding: All participants had at least five years coaching experience in their current coach position. After seasons and seasons coaching, they have already formed certain coaching styles, and their coaching behaviors have fallen into certain patterns, so the way they coach their athletes would not change in a few practice sessions (e.g., two observations per coach).

Lastly, in general the findings of the present study were consistent with the previous studies with regard to the most frequently employed behavioral categories. For example, $50 \%$ or more coaching behaviors exhibited by the participants were Instructional Behaviors; and about 20 $\%$ other coaching behaviors such as Hustle, Praise, Scold; and Management. Specifically, the findings of the current study were partially different from the findings of the previous studies, because half of the participants in the current study came from individual sports. As the results show, five individual sport coaches used the 11 behavioral categories in different ways when compared to the other five team sports coaches (see Table 1 and Figure 1). Regrettably, it was impossible to make a pertinent contrast with the previous studies, because there is no research has been done for identifying coaching behaviors from individual sports.

In conclusions, with respect to the 11 coaching behaviors exhibited by the 10 coaches from the two type of sports, Preinstruction and Questioning coaching behaviors are used more frequently and are more important for the individual sport; Postinstruction and Hustle coaching behaviors are used more frequently and are more important for the team sport. Concurrent Instruction behaviors, and Scold behaviors, however, are utilized by the coaches in both individual and team sports with very similar frequency. Moreover, the following statements may not be conclusive, but could be a valuable reference: the coaches in individual sport tend to use slightly more Praise behavior than coaches in team sport; the coaches in team sport tend to use slightly more Management behavior than coaches in individual sport; and the coaches in both sports appear to use similar amount of Positive Modeling, Negative Modeling and Uncodeable behaviors (see Figure 1).

\section{References}

Claxton, D. B. (1988). A systematic observation of more and less successful high school tennis coaches. Journal of Teaching in Physical Education, 7, 302310.

Darst, P. W., Zakrajsek, D. B., \& Mancini, V. H. (1989). Analyzing physical education and sport instruction. Champaign, IL: Human Kinetics.

Jones, D. F., Housner, L. d., \& Kornspan, A. S. (1997). Interactive decision-making and behavior of experienced and inexperienced basketball coaches. Journal of Teaching in Physical Education, 16, 454468. 
Jones, R. L., Armour, K. M., \& Potrac, P. (2002). Understanding the coaching process: A framework for social analysis. Quest, 54, 34-48.

Lacy, A. C., \& Darst, P. W. (1985). Systematic observation of behaviors of winning high school head football coaches. Journal of Teaching in Physical Education, 4, 256-270.

Lacy, A. C., \& Darst, P. W. (1989). The Arizona State University Observation Instrument (ASUOI). In P. W. Darst, D. B. Zakrajsek, \& V. H. Mancini (Eds.) Analyzing physical education and sport instruction (2nd ed.; pp. 369-377). Champaign, IL: Human Kinetics.

Lacy, A. C., \& Goldston (1990). Behavior analysis of male and female coaches in high school girls' basketball. Journal of Sport Behavior, 13, 29-39.

Millard, L. (1996). Differences in coaching behaviors of male and female high school soccer coaches. Journal of Sport Behaviors, 19, 19-31.

Myers, N. D., Wolfe, E. W., \& Feltz, D. L. . (2005). An Evaluation of the Psychometric Properties of the Coaching Efficacy Scale for Coaches From the United States of America. Measurement in Physical Education and Exercise Science, 9, 135-160.

Ruppert, T., \& Buschner, C. (1989). Teaching and coaching: A comparison of instructional behaviors. Journal of Teaching Education, 9, 49-57.

Segrave, J. O., \& Ciancio, C. A. (1990). An observational study of a successful Pop Warner football coach. Journal of Teaching in Physical Education, 9, 294306.

Sherman, C. A., Fuller, R., \& Speed, H, D. (2000). Gender comparisons of preferred coaching behaviors in Australian sports. Journal of Sport Behavior, 23, 389-406.
Siedentop, D., \& Tannehill, D. (2000). Developing teaching skills in physical education $\left(4^{\text {th }}\right.$ ed.). Mountain View, CA: Mayfield.

Zeng, Z. H., Leung, W. R. (2008). An Examination of Instructional Behaviors of Dual Roles as Athletic Coaches and Physical Educators. Research Quarterly for Exercise and Sport, Suppl, 79, A-70-71.

\section{Correspondence}

Howard Z. Zeng, D. P. E.

Assistant Professor

The City University of New York, Brooklyn College

Department of Physical Education and

Exercise Science

2900 Bedford Avenue, Brooklyn, NY 11210, USA

Tel: 718-951-4427; Fax: 718-951-4541

Email: hzeng@brooklyn.cuny.edu

Raymond W. Leung, D. P. E.

Associate Professor

The City University of New York, Brooklyn College

Department of Physical Education and

Exercise Science

2900 Bedford Avenue. Brooklyn, NY 11210, USA

Email: rleung@brooklyn.cuny.edu

Wei Bian, Ph. D.

Assistant Professor

Physical Education Department

Slippery Rock University

Slipery Rock, PA 16057

Email: weibian@sru.edu

Wenhao Liu, Ph. D.

Assistant Professor

Physical Education Department

Slippery Rock University

Slipery Rock, PA 16057

Tel: 724.738 .2819

Email: wenhao.liu@sru.edu 